\title{
Green procedures for the chemoselective synthesis of acylals and their cleavage promoted by recoverable sulfonic acid based nanoporous carbon (CMK-5-SO $3 \mathrm{H})$
}

\author{
DARYOUSH ZAREYEE*, EHSAN MIRZAJANZADEH and MOHAMMAD ALI \\ KHALILZADEH \\ Department of Chemistry, Qaemshahr Branch, Islamic Azad University, Qaemshahr, Iran \\ e-mail: zareyee@gmail.com
}

MS received 14 January 2015; revised 15 March 2015; accepted 28 March 2015

\begin{abstract}
A selective synthesis of gem-diacetates from the reaction of aldehydes and acetic anhydride in the presence of recyclable nanoporous solid sulfonic acid $\left(\mathrm{CMK}-5-\mathrm{SO}_{3} \mathrm{H}\right)$ under solvent-free reaction conditions is reported. The catalyst was also found to be highly active for deprotection of resulting acylals in water.
\end{abstract}

Keywords. 1,1-Diacetates; acylals; solvent-free; water; $\mathrm{CMK}-5-\mathrm{SO}_{3} \mathrm{H}$; heterogeneous sulfonic acid

\section{Introduction}

From the green chemistry point of view, safety considerations and the simplicity of the process, implementation of methods that avoid the use of harmful organic solvents are fundamental strategies. In this context, with an objective to develop environmentally benign reaction media and conditions for organic reactions with excellent efficiency, solvent-free conditions or using water as the green solvent have aroused considerable attention. ${ }^{1-5}$ Consequently, it is important to investigate new catalysts for organic reactions using less hazardous solvents.

Acylals have often been used as protecting groups for carbonyl compounds because of their stability in neutral and basic conditions and ease of chemoselective preparation in the presence of ketone. ${ }^{6,7}$ Hence, they play an important role for the protection of aldehydes in multistep organic synthesis. Accordingly, methods for their synthesis have received considerable attention.

Generally, acylals can be prepared from aldehydes by treatment with acetic anhydride and Brønsted acids, ${ }^{7-9}$ Lewis acids, ${ }^{10-14}$ or inorganic heterogeneous catalysts. $^{15,16,16-21}$ However, while acknowledging the pioneering advances in this area, some of these methods suffer from disadvantages such as the use of hazardous organic solvents, harsh reaction conditions, low yields, tedious work-up and effluent pollution. Moreover, some of these procedures are not chemoselective in terms of aldehydes and keto carbonyl functional groups. Additionally, a few of the above

*For correspondence mentioned catalysts are claimed to give protection as well as deprotection. Therefore, the development of efficient, recyclable and environmentally benign catalytic methods for these transformations by using nonpolluting reagents and solvents is desirable. Along this line, very recently, we used sulfonic acid nanoreactor SBA-15-Ph- $\mathrm{PrSO}_{3} \mathrm{H}$ in the synthesis of gem-diacetates under solvent-free reaction conditions. In continuation of our studies toward the development of new and cleaner methods for organic transformations, ${ }^{22-25}$ we report herein the results of chemoselective preparation of acylals under solvent-free reaction conditions and deperotection of the corresponding acylals in water as green solvent at room temperature using catalytic amounts of heterogeneous recyclable sulfonic acid CMK-5- $\mathrm{SO}_{3} \mathrm{H}$ (scheme 1).

\section{Experimental}

\subsection{General procedure for the preparation of}

1,1-diacetates

To a mixture of aldehyde $(1 \mathrm{mmol})$ and freshly distilled acetic anhydride $(1.2 \mathrm{mmol})$ was added $(0.023 \mathrm{~g}$, $1 \mathrm{~mol} \%$ ) $\mathrm{CMK}-5-\mathrm{SO}_{3} \mathrm{H}$, and the whole mixture was stirred in a round bottomed flask at room temperature for the appropriate time (table 1). The reaction progress was followed by GC and TLC (eluent, n-hexane:ethyl acetate, 4:1). After completion of the reaction, EtOAc was added to the reaction mixture, and the resulting mixture was filtered and then the extracts concentrated 


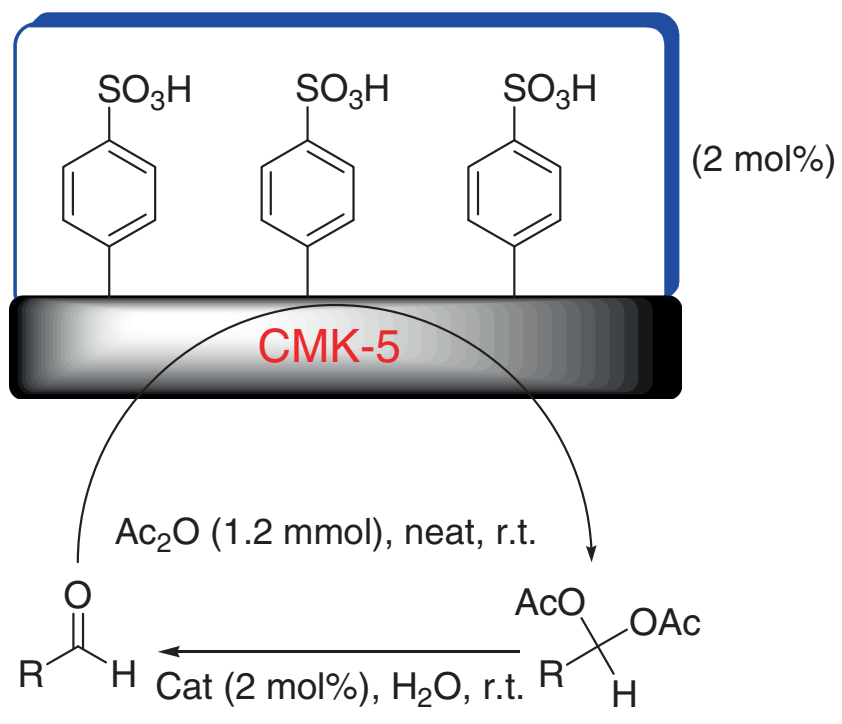

Scheme 1. Synthesis of gem-diacetates and their deprotection using catalyst $\mathrm{CMK}-5-\mathrm{SO}_{3} \mathrm{H}$.

under vacuum. The pure product was isolated following silica gel column chromatography to afford pure acylals. Spectroscopic data for selected examples listed below.

(Entry 1): ${ }^{1} \mathrm{H}$ NMR $\left(400 \mathrm{MHz} ; \mathrm{CDCl}_{3}\right): \delta_{\mathrm{H}}=2.15$ (s, 6H), 7.41-7.55 (m, 5H), $7.70(\mathrm{~s}, 1 \mathrm{H}) ;{ }^{13} \mathrm{C}$ NMR $(100$ $\left.\mathrm{MHz}, \mathrm{CDCl}_{3}\right): \delta_{\mathrm{C}}=20.9,89.7,126.7,128.6,129.8$, $135.5,168.8$.

(Entry 3): ${ }^{1} \mathrm{H}$ NMR $\left(400 \mathrm{MHz} ; \mathrm{CDCl}_{3}\right): \delta_{\mathrm{H}}=2.14$ (s, 6H), 7.33-7.52 (m, 4H), $7.64(\mathrm{~s}, 1 \mathrm{H}) ;{ }^{13} \mathrm{C}$ NMR $(100$ $\left.\mathrm{MHz}, \mathrm{CDCl}_{3}\right): \delta_{\mathrm{C}}=20.8,88.8,125.0,126.8,129.91$, 129.97, 134.5, 137.2, 168.7.

(Entry 14): ${ }^{1} \mathrm{H}$ NMR $\left(400 \mathrm{MHz} ; \mathrm{CDCl}_{3}\right): \delta_{\mathrm{H}}=2.17$ $(\mathrm{s}, 6 \mathrm{H}), 7.70(\mathrm{~s}, 1 \mathrm{H}), 7.73(\mathrm{~d}, 2 \mathrm{H}), 8.28(\mathrm{~d}, 2 \mathrm{H}) ;{ }^{13} \mathrm{C}$ NMR $\left(100 \mathrm{MHz}, \mathrm{CDCl}_{3}\right): \delta_{\mathrm{C}}=20.8,88.3,123.9$, 127.9, 141.8, 148.6, 168.6.

(Entry 20): ${ }^{1} \mathrm{H}$ NMR $\left(400 \mathrm{MHz} ; \mathrm{CDCl}_{3}\right): \delta_{\mathrm{H}}=2.12$ $(\mathrm{s}, 6 \mathrm{H}), \delta_{\mathrm{H}}=2.36(\mathrm{~s}, 3 \mathrm{H}), 7.13-7.15(\mathrm{~d}, \mathrm{~J}=8.4 \mathrm{~Hz}$, $1 \mathrm{H}), 7.31-7.34(\mathrm{t}, \mathrm{J}=7.6 \mathrm{~Hz}, 1 \mathrm{H}), 7.43-7.47(\mathrm{t}, \mathrm{J}=7.6$ $\mathrm{Hz}, 1 \mathrm{H}), 7.65-7.67(\mathrm{~d}, \mathrm{~J}=7.8 \mathrm{~Hz}, 1 \mathrm{H}), 7.92(\mathrm{~s}, 1 \mathrm{H})$.

\subsection{General procedure for deprotection of 1,1-diacetates}

To a stirred mixture of aldehyde $(1 \mathrm{mmol})$ and acetic anhydride (1.2 mmol), CMK-5-SO ${ }_{3} \mathrm{H}(0.023 \mathrm{~g}, 1 \mathrm{~mol} \%)$ was added, and the mixture was stirred at room temperature for the appropriate time (table 1). The reaction progress was followed by GC. After completion of the protection reaction, water $(3 \mathrm{~mL})$ was added to the reaction mixture to perform the deprotection reaction. After completion of the cleavage reaction, $\mathrm{Et}_{2} \mathrm{O}(20 \mathrm{~mL})$ was added and the reaction mixture was filtered to separate the catalyst. The solvent was evaporated under reduced pressure to afford the corresponding aldehydes.

\subsection{Preparation of $C M K-5$}

Templated synthesis of CMK-5 has been achieved using known procedure described by Ryoo and coworkers. ${ }^{26,27}$ Initially, Al was incorporated into SBA$15^{28}$ (molar ratio $\mathrm{Si} / \mathrm{Al}=20$ ) by well dispersion of calcined SBA-15 into an aqueous solution of $\mathrm{AlCl}_{3}$, followed by removal of $\mathrm{H}_{2} \mathrm{O}$ by rotary evaporator and calcination in air. Impregnation of Furfuryl alcohol (FA) into Al-SBA-15 was achieved by incipient wetness infiltration at room temperature. The mixture was then heated up at $80^{\circ} \mathrm{C}$ oven for $16 \mathrm{~h}$ for Al-catalyzed polymerization of FA. The obtained composite was recovered by filtration to remove excess and unpolymerized FA, and washed by EtOH and acetone. The composite was heated to $850^{\circ} \mathrm{C}$ under vacuum at a ramp of $10^{\circ} \mathrm{C} / \mathrm{min}$, and the carbonization was carried out at the same temperature for $3 \mathrm{~h}$ under vacuum. Ordered mesoporous carbon $(\mathrm{CMK}-5)$ was obtained by removal of silica template by $\mathrm{HF}\left(10 \%\right.$ in 1: $\left.1 \mathrm{EtOH}-\mathrm{H}_{2} \mathrm{O}\right)$, washed with copious water and $\mathrm{EtOH}$, and finally dried at $100^{\circ} \mathrm{C}$.

\subsection{Preparation of sulfonated ordered mesoporous carbon $\left(\mathrm{CMK}-5-\mathrm{SO}_{3} \mathrm{H}\right)$}

In a typical modification, $1.2 \mathrm{~g}$ of CMK-5 was added in a three-necked round bottom flask containing $12.0 \mathrm{~g}$ of 4-benzene-diazoniumsulfonate ${ }^{29}$ in $200 \mathrm{~mL}$ of distilled water and $200 \mathrm{~mL}$ of ethanol. Subsequently, the mixture was cooled down to $5^{\circ} \mathrm{C}$ and $200 \mathrm{~mL}$ of $50 \mathrm{wt} \% \mathrm{H}_{3} \mathrm{PO}_{2}$ aqueous solution was added. After stirring for $30 \mathrm{~min}$, another $200 \mathrm{~mL}$ of $\mathrm{H}_{3} \mathrm{PO}_{2}$ aqueous solution was added. The mixture was stirred at $5^{\circ} \mathrm{C}$ for another $30 \mathrm{~min}$. The sulfonic acid functionalized carbon material (denoted as $\mathrm{CMK}-5-\mathrm{SO}_{3} \mathrm{H}$ ) was recovered by filtration, washed thoroughly with distilled water and finally acetone, and dried in an oven at $80^{\circ} \mathrm{C}$.

\section{Results and Discussion}

For our initial protection studies, we carried out the reaction between $1 \mathrm{mmol}$ benzaldehyde, $1 \mathrm{mmol} \mathrm{Ac}_{2} \mathrm{O}$ and $1 \mathrm{~mol} \%$ catalyst at room temperature under solvent free reaction conditions to afford the desired acylal. It was observed that the starting material was consumed after long reaction time $(90 \mathrm{~min})$ as indicated by GC analysis. To optimize the reaction conditions, the reaction was performed using $1.2 \mathrm{mmol}$ acetic anhydride in 
Table 1. CMK-5-SO3H catalyzed solvent-free acylal formation, and acylal deprotection in water.

\begin{tabular}{|c|c|c|c|c|c|}
\hline \multirow[b]{2}{*}{ Entry } & \multirow[b]{2}{*}{ 1,1-Diacetates } & \multicolumn{2}{|c|}{ Preparation } & \multicolumn{2}{|c|}{ Deprotection } \\
\hline & & Time (min) & Yield ${ }^{\mathrm{a}, \mathrm{b}}(\%)$ & Time (min) & Yield $^{\mathrm{a}, \mathrm{c}}(\%)$ \\
\hline 1 & & 10 & 97 & 10 & 98 \\
\hline 2 & & 35 & 97 & 15 & 98 \\
\hline 3 & & 20 & 93 & 15 & 96 \\
\hline 4 & & 20 & 94 & 15 & 99 \\
\hline 5 & & 40 & 89 & 25 & 92 \\
\hline 6 & & 35 & 98 & 15 & 92 \\
\hline 7 & & 25 & 98 & 15 & 93 \\
\hline 8 & & 20 & 99 & 15 & 95 \\
\hline 9 & & 20 & 99 & 20 & 96 \\
\hline 10 & & 30 & 99 & 10 & 94 \\
\hline 11 & & 30 & 95 & 10 & 95 \\
\hline 12 & & 40 & 98 & 10 & 90 \\
\hline 13 & & 25 & 95 & 10 & 96 \\
\hline $14^{\mathrm{d}}$ & & 45 & 98 & 15 & 90 \\
\hline $15^{\mathrm{d}}$ & & 50 & 90 & 20 & 89 \\
\hline
\end{tabular}


Table 1. continued.

\begin{tabular}{|c|c|c|c|c|c|}
\hline \multirow[b]{2}{*}{ Entry } & \multirow[b]{2}{*}{ 1,1-Diacetates } & \multicolumn{2}{|c|}{ Preparation } & \multicolumn{2}{|c|}{ Deprotection } \\
\hline & & Time (min) & Yield $^{\mathrm{a}, \mathrm{b}}(\%)$ & Time (min) & Yield $^{\mathrm{a}, \mathrm{c}}(\%)$ \\
\hline 16 & & 10 & 98 & 35 & 92 \\
\hline 17 & & 10 & 96 & 15 & 93 \\
\hline 18 & & 15 & 97 & 15 & 94 \\
\hline 19 & & 25 & 94 & 20 & 89 \\
\hline 20 & & 25 & 92 & 20 & 90 \\
\hline 21 & & 30 & 90 & 40 & $92^{\mathrm{e}}$ \\
\hline 22 & & $24 \mathrm{~h}$ & No reaction & - & - \\
\hline
\end{tabular}

${ }^{\mathrm{a}} \mathrm{GC}$ Yields. ${ }^{\mathrm{b}}$ Reaction conditions: aldehyde $(1 \mathrm{mmol}), \mathrm{Ac}_{2} \mathrm{O}(1.2 \mathrm{mmol}), \mathrm{CMK}-5-\mathrm{SO}_{3} \mathrm{H}(2 \mathrm{~mol} \%)$, room temperature, solvent-free. ${ }^{\mathrm{c}}$ All deprotection reactions were carried out at room temperature using water as solvent. ${ }^{\mathrm{d}} 1.5 \mathrm{mmol}^{\mathrm{Ac}} \mathrm{C}_{2} \mathrm{O}$ was

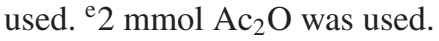

the presence of 2 mol\% catalyst (scheme 1), and considerable improvement was observed in the yield of product after 10 minute (table 1, entry 1). It is also important to mention that when the same reaction was performed without catalyst and no product was obtained.

To generalize the scope and versatility of this protocol, different substituted aldehydes were used for the synthesis of substituted acylals. Aldehydes bearing both electron-donating and electron-withdrawing substituents resulted in the corresponding acylals in good to excellent yields (table 1, entries 1-15). The catalyst was also found to be active for the preparation of acylal from sterically hindered aldehyde, 1naphtaldehyde (table 1, entry 16). Notably, furan-2carbaldehyde and thiophene-2-carbaldehyde as acid sensitive substrates gave the related 1,1-diacetates in excellent yields (table 1, entries 17-18). Also the present protocol works well for aliphatic aldehydes to give the corresponding geminal diacetates in excellent yields (table 1, entries 19-20). When the reaction was extended towards hydroxybenzaldehydes, the hydroxyl group was also protected as acetate (table 1, entry 21).

Under the selected conditions, acylation of ketones was not successful and the starting material was recovered unchanged even when the reaction mixture was

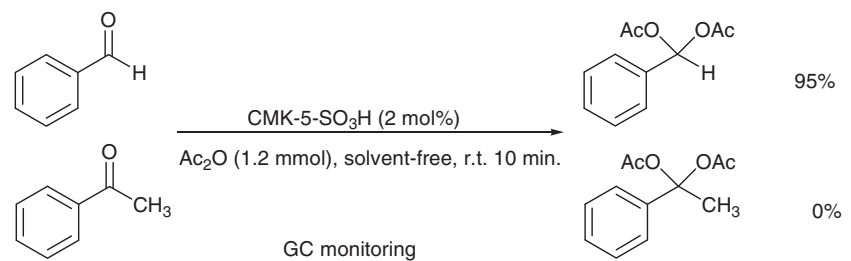

Scheme 2. Chemoselectiveacylal formation from benzaldehyde in the presence of acetophenone.

stirred for $24 \mathrm{~h}$ (table 1, entry 22). Encouraged by this result, in a competitive experiment, equimolecular mixture of benzaldehyde and acetophenone was allowed to react with $1.2 \mathrm{mmol}$ of acetic anhydride under the same reaction condition, gave only 1,1-diacetates of benzaldehyde while the ketone functionality remained unaffected (scheme 2). Hence, chemoselective acylal formation from aldehydes in the presence of ketones could be achieved with this catalytic system.

The feasibility of recyclable properties of the catalyst was examined through a series of sequential synthesis of acylal from benzaldehyde and $\mathrm{Ac}_{2} \mathrm{O}$ as model substrates. The catalyst was easily separated by filtration after completion of each run, with addition of ethyl acetate. Interestingly, the recycled catalyst was used for 
Table 2. Comparison of various methods for acylal synthesis from 4-nitrobenzaldehyde.

\begin{tabular}{|c|c|c|c|c|c|c|}
\hline Entry & Catalyst (mol\%) & Equiv. of $\mathrm{Ac}_{2} \mathrm{O}$ & Solvent & $\mathrm{T}\left({ }^{\circ} \mathrm{C}\right)$ & Time $(\min /[\mathrm{h}])$ & Yield (\%) \\
\hline 1 & CMK-5-SO ${ }_{3} \mathrm{H}(2)$ & 1.2 & Solvent free & $\mathrm{rt}$ & 50 & $90^{\mathrm{a}}$ \\
\hline 2 & CAN (10) & 2 & Solvent free & $\mathrm{rt}$ & [24] & $96[12]^{\mathrm{b}, \mathrm{c}, \mathrm{d}}$ \\
\hline 3 & $\mathrm{KHSO}_{4}(10)$ & 2 & Solvent free & $\mathrm{rt}$ & 90 & $96[27]^{b, c}$ \\
\hline 4 & LiOTf (20) & $5-8$ & Solvent free & $\mathrm{rt}$ & [15] & $94[28]^{b, c, d, e}$ \\
\hline 5 & $\mathrm{Cu}(\mathrm{OTf})_{2}(2.5)$ & 3 & $\mathrm{CH}_{2} \mathrm{Cl}_{2}$ & $\mathrm{rt}$ & [4] & $94[29]^{\mathrm{c}, \mathrm{d}, \mathrm{f}}$ \\
\hline 6 & $\mathrm{AlPW}_{12} \mathrm{O}_{40}$ & 1 & $\mathrm{CH}_{2} \mathrm{Cl}_{2}$ & $\mathrm{rt}$ & 45 & $89[30]^{\mathrm{C}, \mathrm{f}}$ \\
\hline 7 & $\operatorname{In}(\mathrm{OTf})_{3}$ & $1.2-1.5$ & $\mathrm{CH}_{2} \mathrm{Cl}_{2}$ & $\mathrm{rt}$ & 15 & $99[11]^{\mathrm{C}, \mathrm{f}}$ \\
\hline
\end{tabular}

${ }^{\mathrm{a}}$ This work. ${ }^{\mathrm{b}}$ High catalyst loading. ${ }^{\mathrm{c}}$ Non-recoverable catalyst. ${ }^{\mathrm{d}}$ Long reaction time. ${ }^{\mathrm{e}}$ Excess amount of Ac $\mathrm{c}_{2} \mathrm{O} .{ }^{\mathrm{f}}$ Toxic solvent $\left(\mathrm{CH}_{2} \mathrm{Cl}_{2}\right)$.

eight consecutive runs without any appreciable change in catalytic activity.

In order to show the efficiency of the present method, we have compared our results obtained from the acetylation of 4-nitrobenzaldehyde with acetic anhydride catalyzed by $\mathrm{CMK}-5-\mathrm{SO}_{3} \mathrm{H}$ with other results reported in the literature. As can be seen in table 2, this method avoids some disadvantages of other procedure such as long reaction times ${ }^{12,31,32}$ toxic solvents, ${ }^{32}$ excess reagents, ${ }^{31,32}$ and non-recoverable catalyst. ${ }^{11,12,29-33}$

In addition to these results, to evaluate the cleavage of resulting acylals, we also investigated the deprotection procedure by addition of water as a green solvent to the reaction mixture. Indeed, when the formation of 1,1-diacetates were completed, water was added. All reactions were performed at room temperature in good to high yields (scheme 1, table 1).

\section{Conclusion}

To summarize, we have reported an efficient, green, and chemoselective method for the preparation of gem-diacetates from aldehydes under solvent-free reaction conditions at room temperature using heterogeneous $\mathrm{CMK}-5-\mathrm{SO}_{3} \mathrm{H}$. Deprotection of the resulting 1,1diacetates can also be achieved by addition of water, a green solvent. The elimination of toxic solvents, simple workup procedure, excellent catalytic capacity and outstanding recyclability of catalyst make a valid contribution to the existing methodologies.

\section{Supplementary Information}

Schematic preparation of CMK-5- $\mathrm{SO}_{3} \mathrm{H}$ (figure $\mathrm{S} 1$ ), TGA (figure $\mathrm{S} 2$ ), BJH (figure $\mathrm{S} 3$ ), $\mathrm{N}_{2}$ ads-des (figure S4), and XRD diagrams for CMK-5 (figure S5) and $\mathrm{CMK}-5-\mathrm{SO}_{3} \mathrm{H}$ (figure $\mathrm{S} 6$ ), TEM image for recovered catalyst (figure S7) and copy of ${ }^{1} \mathrm{H}$ and ${ }^{13} \mathrm{C}$ spectra for some products are available at www.ias.ac.in/chemsci.

\section{Acknowledgements}

The authors acknowledge the Islamic Azad University of Qaemshahr Research Councils for support of this work.

\section{References}

1. Martins M A P, Frizzo C P, Moreira D N, Buriol L and Machado P 2009 Chem. Rev. 1094140

2. Walsh P J, Li H and De Parrodi C A 2007 Chem. Rev. 1072503

3. Toda F and Tanaka K 2000 Chem. Rev. 1001025

4. Li C J and Chan T H 1999 Tetrahedron 5511149

5. Li C J 2005 Chem. Rev. 1053095

6. Greene T W and Wuts P G M 1999 In Protective Groups in Organic Synthesis 3rd ed. (New York: John Wiley and Sons) p. 306

7. Gregory M J 1970 J. Chem. Soc. B. 1201

8. Jin T S, Sun G, Li Y W and Li T S 2002 Green Chem. 4 255

9. Heravi M M, Bakhtiari K and Bamoharram F F 2006 Catal. Commun. 7499

10. Aggen D H, Arnold J N, Hayes P D, Smoter N J and Mohan R S 2004 Tetrahedron 603675

11. Ghosh R, Maiti S, Chakraborty A and Halder R $2004 \mathrm{~J}$. Mol. Catal. A: Chem. 21549

12. Roy S C and Banerjee B 2002 Synlett. 1677

13. Zhang X, Li L and Zhang G 2003 Green Chem. 5464

14. Smitha G and Reddy Ch S 2003 Tetrahedron $\mathbf{5 9} 9571$

15. Olah G A and Mehrotra A K 1982 Synthesis 962

16. Curini M, Epifano F, Marcotullio M K, Rosati O and Nocchetti M 2002 Tetrahedron Lett. 432709

17. Kamble V T, Jamode V S, Joshi N S, Biradara A V and Deshmukh R Y 2006 Tetrahedron Lett. 475573

18. Wu H, Shen Y, Fan L Y, Wan Y and Shi D Q 2006 Tetrahedron 627995

19. Jermy B R and Pandurangan A 2008 Catal. Commun. 9 577

20. Javad Kalbasi R, Massah A R and Shafiei A 2011 J. Mol. Catal. A: Chem. 33551

21. Shirini F, Mamaghani M and Seddighi M 2013 Catal. Commun. 3631

22. Karimi B and Zareyee D 2008 Org. Lett. 103989

23. Karimi B and Zareyee D 2009 J. Mater. Chem. 198665 
24. Zareyee D, Asghari R and Khalilzadeh M A 2011 Chin. J. Catal. 321864

25. Zareyee D, Moosavi S M and Alaminezhad A $2013 \mathrm{~J}$. Mol. Catal. A: Chem. 378227

26. Joo S H, Choi J, Oh I, Kwak J, Liu Z, Terasaki O and Ryoo R 2001 Nature 412169

27. Kurk M, Jaroniec M, Kim T W and Ryoo R 2003 Chem. Mater. 152815

28. Yu C, Fan J, Tian B, Zhao D and Stucky G D 2002 Adv. Mater. 141742
29. Bouchet M J, Rendon A, Wermuth C G, Goeldner M and Hirth C 1987 J. Med. Chem. 302222

30. Heravi M M, Bakhtiari K, Taheri S and Oskooie H A 2005 Green Chem. 7867

31. Karimi B and Maleki J 2003 J. Org. Chem. 68 4951

32. Chandra K L, Saravanan P and Singh V K 2000 Synlett 359

33. Firouzabadi H, Iranpoor N, Nowrouzi F and Amani K 2003 Tetrahedron Lett. 443951 